\title{
Research on Steel Structure Construction Technology and Risk Man- agement Based on BIM
}

\author{
(1. Dongying City, Shandong Shi Da Shenghua Chemical Group Co., Ltd. Dongying 257000, Shandong)
}

\section{(2. Sinopec Shengli Oilfield, Dongying, Shandong 257000)}

\section{Introduction}

With the continuous development of China's overall economy, the construction industry has been promoted for development. As a pillar industry of economic development, there are many problems in the construction industry: the output value is too high and the efficiency is low. As the state puts forward the structural reform policy of the supply side, the development of the construction industry has also entered into the trend of structural reform. So as to enhance the competitiveness of the construction industry and promote the revitalization of the construction industry. We all know that the construction industry needs a large number of construction units in close cooperation projects, accurate information transmission is very important, in addition to the scale of steel construction has been expanding, the structure has become increasingly complex, then the construction project management The process is also facing many problems, which requires construction information to solve the problem.

BIM building information model technology is an important way to solve the above problems, BIM through the integration of building construction process of various data information for the construction departments to provide detailed and accurate data information, thereby promoting the efficiency of construction, while improving the management of the building Construction control management. In addition, BIM building information model technology to steel structure and other complex construction to provide more possibilities, with the scale of steel construction continues to expand, then the construction process in the process of facing more and more risks, At the same time, largescale steel structure construction process is also faced with a variety of data and information is large, the information is not smooth and other issues, which gave construction management has brought great trouble, therefore, the use of BIM building information model technology to deal with steel Structural construction problems and problems facing is very important, but also the construction of the future development trend.

\section{Steel structure construc- tion technology problems}

1.1 Component structure is complex, design, construction, management difficulties

In general, the building design unit will use the AutoCAD drawing software to decompose the architectural content in the building, but this method has great limitations, especially in the case of complex design face, the accuracy of this drawing software is difficult to meet the design requirements.

1.2 Information cross, sharing the workload

In the steel structure construction process, not only the traditional construction of the operating sector, as well as steel design and construction departments, while the need for two constantly exchange of information, close with the smooth

\begin{abstract}
In recent years, with the rapid development of the construction industry, the new building structure system and the personalized building shape are constantly influencing people's vision. The large-scale and complicated construction is a major feature of the development of the building structure. The innovation of the structure has increased the risk in the construction process and put forward new technical problems for the construction of the building structure. The feasibility of the construction scheme and the safety of the construction process should be fully guaranteed. In the environment of industrial upgrading, building information model BIM has been more and more applications. The traditional steel structure construction technology has the problems of the complex structure of components, the large workload of information sharing and so on. It can solve this problem by using BIM modeling, visualization application and information management sharing application. BIM technology through the construction project decision-making stage, design stage and construction stage, can solve the traditional risk management in the stage, inefficient and passive wins and other issues.
\end{abstract}

Key words: BIM technology; steel structure construction; risk management

Published online: 15th July, 2017

completion of the smooth. However, in the actual construction of the actual process because of 
the huge amount of information, and just stay in relying on the drawings to convey information on the model, has been unable to meet the current requirements of steel construction.

\subsection{Uncontrollable factors and more}

In the ordinary construction process encountered in the impact of factors, the same will be encountered in the construction of steel construction. Such as the construction of the climate is not suitable for construction, it will lead to the construction of the stop, thus affecting the construction period; and, for example, in the construction process of the lack of construction materials, construction plans suddenly change, these factors will be unable to control the construction influences.

\section{Application of BIM Technolo- gy in Steel Structure Construc- tion}

\subsection{Dynamic modeling}

BIM building information model technology can be built according to its own database building model, through the BIM database can build a detailed architectural model, including the specific shape of the building, location, size, construction materials and construction process. Similarly, the use of BIM building information model technology can quickly build steel frame 3D model, the model is established, the construction unit can be based on detailed model information construction.

\subsection{Parametric design}

Whether it is the construction of ordinary building model or the construction of steel frame structure, it is necessary to design and calculate the detailed parameters. BIM building information model technology has been necessary to build the construction of the building have been parameterized, then the user only need to click on the relevant interface in the user interface, so long for the steel structure model can automatically design the corresponding parameters. If the parameters provided by BIM are not yet able to meet the building model parameters required by the user, the user can also set the relevant parameters in a custom way.

\subsection{Visualization applications}

BIM building information model technology has a visual management mode of operation, through the use of BIM technology, construction workers can timely share the progress of construction data, usually exchange more construction information, so as to improve the efficiency of construction management. By adding the specific parameter information of the steel frame structure to the BIM management software, the model data can be changed with the addition of data, so that it can be adjusted in time.

\subsection{Information sharing manage- ment}

In the specific construction process, the construction manager uses BIM technology to carry on the real-time monitoring and the following to the operator, the operation object, the operation station and so on, constantly collects the building information data, and fully understands the construction process and the time in detail Construction of building construction model. So that managers can quickly and easily extract the data they want to understand the information.

\section{Application of BIM Technolo- gy in Risk Management of Steel Structure Construction}

3.1 Risk management in steel structure construction

\section{$\square$ The stage of risk management}

The traditional construction project management is divided into a number of stages, so the face of a variety of risk control management is also a stage, each stage will have different risks, then the construction of the managers are in different stages of risk At any time to make targeted to deal with the corresponding treatment program.

The low efficiency of risk man- agement

With the continuous improvement of the structure and scale of the building, then the risk factors also increased, which requires different construction teams, between the construction team and management personnel in a timely and effective communication. In the original construction, the exchange of this information is mostly through the paper documents to communicate, which greatly affected the efficiency of risk management control.

\section{$\square$ Synergies in risk management}

In the traditional construction management mode, the main control of the object is concentrated in a single factor to go, but did not take into account all the factors. But in fact all the risk factors are the constraints of the link, in order to risk management to a comprehensive control, it must be all the associated risk factors are in-depth analysis, otherwise it will cause very serious consequences.

\section{$\square$ Risk management of the passive}

In the traditional construction management model, if there is no comprehensive consideration of the comprehensive risk factors, then there may be unexpected risks exist, this time will lead to passive management.

\subsection{Application of BIM Technology in Risk Management}

\section{$\square$ Decision stage}

In the early stages of construction of the project requires the construction of the timely decision-making, this stage called the decision-making stage. At this time usually need to work with the owners' in-depth demonstration, to find the best option. Using BIM technology visualization, the construction of all the alternatives to demonstrate one by one, taking into account a variety of risk factors, and targeted to deal with the risk of the strategy. Through the use of BIM technology platform, timely feedback into the BIM technology model to go, so as to quickly 
find the best solution strategy.

\section{Design stage}

As shown in Figure 1, through the BIM technology to establish the main building model, the overall structure of the model, the relevant pipeline model, electrical system construction model, and then through the overall combination of the formation of BIM model, if there is a need to modify the place, To make changes, which greatly reduces the workload. And then through the simulation of the collision analysis, this time will solve a single sheet cannot solve the problem, the construction operator can be completed according to the report to review the appropriate changes, which will not appear in the latter part of the possibility of modification.

\section{$\square$ Construction phase}

In the construction phase, the use of BIM technology real-time sharing function, the owners, construction units, design units, supervision units of data in a platform on the exchange of mutual collision. BIM technology can also combine the building model with the construction schedule to form a 4D model, not only can clearly see the construction of the situation, but also to grasp the construction time. According to the above 4D model, we can track the status of construction resources in real time, and we can pay attention to the progress of construction time while we find the problem correction problem.

\section{Engineering examples}

This paper chooses a construction project as a practical example to illustrate. The actual construction area of the building is $30000 \mathrm{~m}^{2}$, of which $272726.5 \mathrm{~m} 2$ on the ground area, the overall building area of $359376.3 \mathrm{~m}^{2}$, the height of $440 \mathrm{~m}$. The building is composed of towers and podium two parts, one of the tower is the arm truss, the core tube structure. The three core trusses between the core of the tower and the main frame of the column are connected with concrete-filled steel and steel beams.

\subsection{Application of steel structure in construction}

In the specific construction of the project, the first use of BIM building information model technology, the construction process of construction materials, structural design, installation design, project model construction parts, process, workshop information, worker information and other specific information, and then converted into the corresponding digital information, through the Internet to share the details of the common to the construction staff.

\subsection{Application in Steel Structure Vi- sualization}

The data of the collected data is updated in the project building model in time, and then the actual construction progress is compared with the data in the visualization model to realize the visual management mode. From the specific cost of construc- tion, through the BIM technology to calculate the cost of construction projects, so the cost of construction investment costs reasonable control.

\subsection{In cloud computing applications}

BIM technology and cloud computing are connected, and then through the cloud analysis of the corresponding data, can achieve centralized management of building data, then the construction unit is also in accordance with their own requirements to extract data.

\subsection{Application in materials}

BIM technology to use the use of building materials, the use of personnel, the use of equipment to establish the corresponding library, weapons, the establishment of electronic tags, saving a lot of manpower costs. The combination of radio frequency identification technology and material model, material location can be set to electronic tags, a substantial increase in the construction speed and material utilization.

4.5 In the application of information intelligence management

After the completion of the construction project, but also need to carry out careful and meticulous inspection and inspection work, the use of electronic label technology for acceptance of construction projects. After the acceptance, BIM technology will be the construction of the construction process of the drawings and other information all deposited

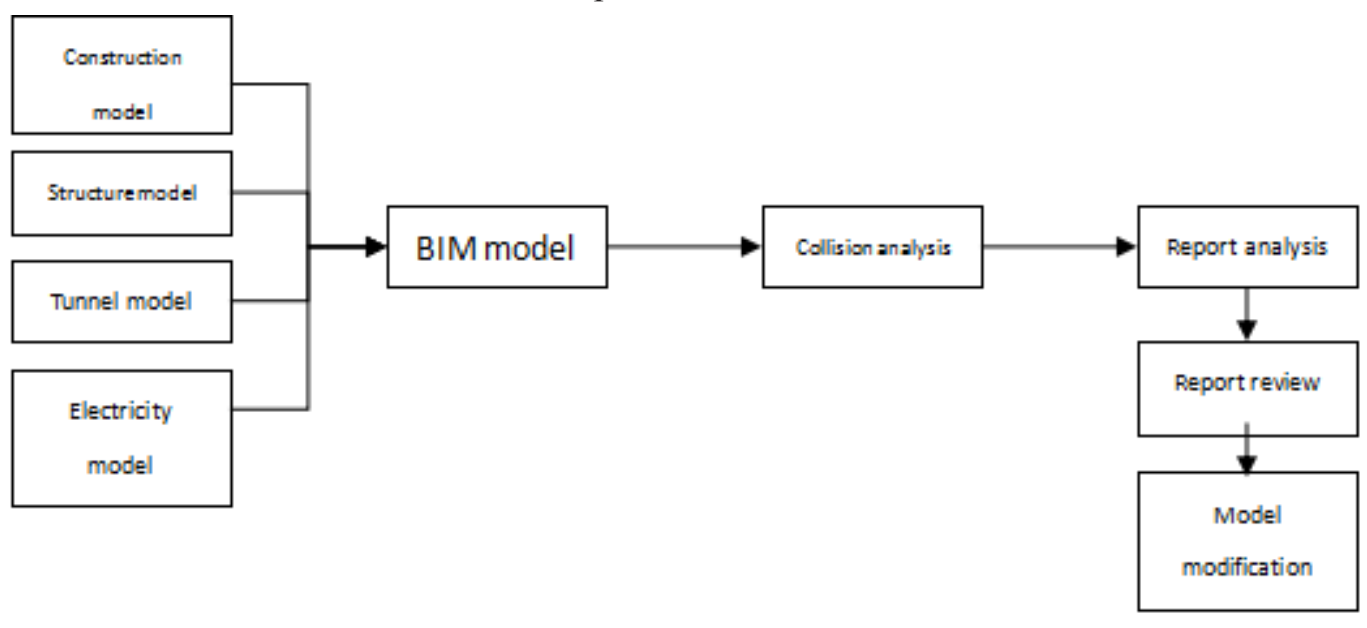

Figure 1 Collision simulation process 
into the database, easy to use. At the same time BIM technology can also complete the project to track, collect specific data and analysis, so as to establish the relevant files.

\section{Conclusion}

(1) Application of BIM technology in steel structure construction can solve the problems of complex structure, design, construction and management difficulties in traditional steel structure and difficulties in information communication.

(2) BIM technology in the construction projectriskmanagement, throughout the decision-making stage, design stage and construction stage, to solve the traditional risk management in the stage, inefficiency, passive and other issues.

\section{References}

[1] Zhang Zubin. BIM technology in the construction of steel structure management application $[\mathrm{J}]$. Green building materials.2017 (04)

[2] Pang Li'an. Modern steel structure building design $[\mathrm{J}]$. Science and Technology Innovation and Application.2016 (05)

[3] Zhao Jingyuan. BIM technology based on the building structure of computer optimization design $[\mathrm{J}]$. Automation and Instrumenta- tion.2016 (12)

[4] Tang Youxiu.BIM technology in the field of civil engineering construction application [J]. Jiangxi Building Materials.2017 (06)

[5] Zhang Yang. BIM technology in the construction safety management application research [J]. Green building materials.2017 (04)

[6] Huang Zhenbang. Large span steel structure construction technology and BIM application research [D]. Beijing University of Architecture.2016

[7] Huang Zihao. BIM technology in steel structure engineering application research [D]. South China University of Technology.2013

[8] Wu Huiqun. On the current BIM technology in China's application problems and improvement measures [J]. Construction supervision.2016 (08)

[9] Zhou Yan. BIM-GIS technology in the construction management visualization application [J]. Automation and Instrumentation.2016 (6)

[10] Sun Linlin. BIM technology in the construction project management application $[\mathrm{J}]$. Residential and real estate.2016 (21)

[11] Ai Siping. BIM technology in the construction industry in the application [J]. Journal of Anhui Water
Conservancy and Hydroelectric Vocational and Technical College.2017 (01)

[12] Deng Xin. Based on BIM and RFID integrated construction site safety monitoring system construction and function of [J]. Automation and Instrumentation.2017 (1)

[13] GAO Li-xiang, XIE Ping-rong. Application and Problems of Steel Structure in High Layer [J]. China Architecture Metal Structure.2013 (06)

[14] Xie Zhiguo. Steel structure construction technology development and improvement of my opinion [J]. China Construction Metal Structure.2013 (22)

[15] Zeng Qing.Study on seismic design analysis method of steel structure $[\mathrm{J}]$. Environmental Building Materials.2017 (04)

[16]Hyojoo Son, Sungwook Lee, Changwan Kim. What drives the adoption of building information modeling in design organizations? An empirical investigation of the antecedents affecting architects' behavioral intentions[J]. Automation in Construction.2015

[17]Jason Lucas, Tanyel Bulbul, Walid Thabet. An object-oriented model to support healthcare facility information management[J]. Automation in Construction.2012 